\title{
Article \\ Stereolithography Apparatus Evolution: Enhancing Throughput and Efficiency of Pharmaceutical Formulation Development
}

\author{
Carlo Curti (, Daniel J. Kirby (1) and Craig A. Russell * \\ School of Pharmacy, Aston University, Aston Triangle, Birmingham B4 7ET, UK; curtic@aston.ac.uk (C.C.); \\ D.J.KIRBY1@aston.ac.uk (D.J.K.) \\ * Correspondence: c.russell6@aston.ac.uk; Tel.: +44-01212043077
}

Citation: Curti, C.; Kirby, D.J.; Russell, C.A. Stereolithography Apparatus Evolution: Enhancing Throughput and Efficiency of Pharmaceutical Formulation Development. Pharmaceutics 2021, 13, 616. https://doi.org/10.3390/ pharmaceutics13050616

Academic Editor: Natalja Genina

Received: 29 March 2021

Accepted: 21 April 2021

Published: 25 April 2021

Publisher's Note: MDPI stays neutral with regard to jurisdictional claims in published maps and institutional affiliations.

Copyright: (c) 2021 by the authors. Licensee MDPI, Basel, Switzerland. This article is an open access article distributed under the terms and conditions of the Creative Commons Attribution (CC BY) license (https:/ / creativecommons.org/licenses/by/ $4.0 /)$.
Abstract: Pharmaceutical applications of 3D printing technologies are growing rapidly. Among these, vat photopolymerisation (VP) techniques, including Stereolithography (SLA) hold much promise for their potential to deliver personalised medicines on-demand. SLA 3D printing offers advantageous features for pharmaceutical production, such as operating at room temperature and offering an unrivaled printing resolution. However, since conventional SLA apparatus are designed to operate with large volumes of a single photopolymer resin, significant throughput limitations remain. This, coupled with the limited choice of biocompatible polymers and photoinitiators available, hold back the pharmaceutical development using such technologies. Hence, the aim of this work was to develop a novel SLA apparatus specifically designed to allow rapid and efficient screening of pharmaceutical photopolymer formulations. A commercially available SLA apparatus was modified by designing and fabricating a novel resin tank and build platform able to 3D print up to 12 different formulations at a single time, reducing the amount of sample resin required by 20 -fold. The novel SLA apparatus was subsequently used to conduct a high throughput screening of 156 placebo photopolymer formulations. The efficiency of the equipment and formulation printability outcomes were evaluated. Improved time and cost efficiency by $91.66 \%$ and $94.99 \%$, respectively, has been confirmed using the modified SLA apparatus to deliver high quality, highly printable outputs, thus evidencing that such modifications offer a robust and reliable tool to optimize the throughput and efficiency of vat photopolymerisation techniques in formulation development processes, which can, in turn, support future clinical applications.

Keywords: 3D printing; stereolithography; digital light processing; solid oral dosage forms; formulation development; personalised medicine; cost effectiveness; lean production; sustainability

\section{Introduction}

Three-dimensional (3D) printing is defined as a set of manufacturing technologies used to make parts by adding material in a layer-by-layer fashion [1]. Due to its appealing features, 3D printing has received great interest from the pharmaceutical field, especially following the 2015 FDA approval of the first 3D-printed drug product, Spritam. Since then, interest has aroused fast and, so far, several 3D-printing technologies have been used, understood, and improved [2], and particular emphasis has been posed on its potential applications in delivering personalised medicine [3]. This particular use has been motivated by the intrinsic flexibility of 3D printers, that are able to fabricate solid oral dosage forms with bespoke properties potentially with no need to alter the formulation [4], in contrast to conventional tableting techniques which are not customizable at reasonable costs and only have limited geometries achievable. For example, the recently FDA-approved T19 rheumatoid arthritis drug, designed as a chronotherapeutic drug delivery system targeting the circadian symptoms of the disease, achieves its particular release profile thanks to the complex inner geometry fabricated through 3D printing [5]. Such an approach would 
complement the standard mass production of medicines, embracing a highly patient-centric method foreseen to revolutionise pharmacotherapy [6].

Promising 3D printing applications currently rely on Fused Deposition Modelling (FDM), Selective Laser Sintering (SLS) and vat photopolymerisation (VP) techniques [7]. Each of these technologies differ in the way the layers are built; for example, in FDM a drug loaded filament is thermally extruded into the desired geometry, while in SLS thin layers of powdered raw material are sintered by a laser [8]. VP techniques, such as Stereolithography (SLA) and Digital Light Processing (DLP) instead operate through light-induced curing of photosensible resins [8].

Formulation of solid oral dosage forms with different 3D printing methods mainly affect features such as drug release, mechanical properties, and external appearance. FDM and related techniques have been used for a wide range of applications and allowed the manufacturing of variously engineered solid dosage forms [9-12], while SLS has been investigated for its power to fabricate rapidly disintegrating tablets [13-17]. SLA and DLP 3D printing have been instead used to fabricate controlled release dosage forms, hydrogels and polypills [7,18-23].

While FDM currently stands as a frontrunner in the advanced development of 3Dprinted solid oral dosage forms, its disadvantages should be considered as, for example, process limitations restrict the number of drugs that can be used due to potential processinduced thermal degradation [24,25]. This is especially true considering that FDM is generally coupled with hot-melt extrusion, thus doubling the incidence of thermal challenge and chance of stability issues [26]. Furthermore, developing drug-loaded filaments with satisfactory mechanical properties for extrusion and 3D printing can be challenging [27]. Similarly, heat-induced degradation could also affect SLS 3D-printed products due to the rise in temperature caused by the sintering activity of the laser [7]. Additionally, the required feed-stock material can suffer from flowability issues, particularly when the powder is thinly spread at the completion of each layer [28].

Such limitations are not shared by VP techniques, as both SLA and DLP do not rely on heat for fabrication and do not require powders. Instead, each layer is manufactured by either a laser beam (SLA) or a digital projector screen (DLP) inducing the polymerisation of a drug-loaded resin. VP is also a very accurate process with high printing resolution, enabling the fabrication of solid oral dosage forms with greater patient acceptability over other techniques such as FDM and SLS $[7,29,30]$.

However, pharmaceutical applications of VP technologies still account for the smaller share and remain underdeveloped $[7,31]$. This is particularly dependent upon throughput limitations related to the impossibility of printing simultaneously using low volumes of different resins [21], thus making formulation development processes time consuming and cost inefficient. Although some discontinuous methods to overcome this limitation have been suggested [32], the overall process needs to be improved.

Furthermore, limitations are posed by the lack of materials suitable for VP; commercially available photopolymer resins have been designed mainly for engineering purposes, where tough and resistant structures are needed with high crosslinking observed in the polymerised networks $[33,34]$. However, from a pharmaceutical perspective, such mechanical attributes are not desirable as orally administered dosage forms should completely break down to release their drug content and to then be eliminated with no risk of leaving tablet fragments in the gastrointestinal tract [35]. Additionally, despite the existence of biocompatible commercially available resins designed for special applications, such as dentistry [36,37], only a limited number of photopolymer formulations have been investigated for pharmaceutical applications $[20,22,32,38]$. Such limitations, therefore, lay the foundations for an extensive screening of photopolymer formulations and their respective evaluation. SLA and DLP 3D printers currently on the market are designed to operate using large volumes of a single resin at any one time [21] allowing for large prints, which can be advantageous in prototyping and similar applications. This is not required or desirable in pharmaceutical formulation development and, consequently, without addressing such 
aspects, developing novel formulations would require an unnecessarily large amount of resin resulting in a less than economical process.

Hence, the aim of this work was to design and fabricate a novel SLA apparatus able to 3D print solid dosage forms using low volumes and multiple formulations at the same time, with the view to maximising throughput and cost-effectiveness of the technique. Lean production principles of avoiding waste related to 'inventory', 'overproduction' and 'waiting' were followed as a general guideline to identify critical areas to address to improve the technique for pharmaceutical applications [39]. Furthermore, the purpose of developing a novel SLA apparatus arrangement was to employ a high throughput screening of novel pharmaceutical photopolymer resins to address the lack of formulations for VP technologies. Screened formulations were evaluated based on their printability outcomes with the view to develop a pool of multi-purpose, drug-loadable resins that can be flexibly used to deliver safe, effective, and personalised dosage forms.

\section{Materials}

Clear resin V4.0 (Formlabs Inc., Somerville, MA, USA) was purchased as a commercially available photopolymer for SLA 3D printing. Clear silicon glue was purchased from Loctite (Henkel Corp., Düsseldorf, Germany). Aluminium tape was acquired from 3M, USA. Propan-2-ol was obtained from Fisher Scientific, Loughborough, UK. A 150 (width) $\times 150$ (depth) $\times 100$ (height) mm H30-6082-T6 aluminium alloy block was purchased from John Keatley Metals (KeatleyMetals Ltd., Birmingham, UK). Polyethylene glycol diacrylate (PEGDA-MW 250, 575 and 700) and N-vinyl-pyrrolidone were used as reactive oligomers and monomer, respectively. Diphenyl 2,4,6-trimethyl benzoyl phosphine oxide (TPO) was used as photoinitiator at a concentration of $1 \%, 0.5 \%, 0.1 \%$ and $0.05 \%(w / w)$. Polyethylene glycol 300 (PEG 300), propylene glycol and glycerol were selected as liquid non-reactive fillers at a concentration of $12.5 \%, 25 \%$ and $50 \%(w / w)$. All chemical reagents were purchased from Sigma-Aldrich, Gillingham, UK.

\section{Methods}

\subsection{Stereolithography Apparatus}

A Form 2 SLA 3D printer (Formlabs Inc., Somerville, MA, USA) was used as a desktop stereolithography apparatus to manufacture all the formulations presented in this work. The Form 2 3D printer is equipped with a $405 \mathrm{~nm}$ laser and has a build volume of 145 (width) $\times 145$ (depth) $\times 175$ (height) $\mathrm{mm}$. The feedstock material consists of a photopolymer resin contained in a $200 \mathrm{~mL}$ vat. Printed objects are formed on a build platform made of aluminium and plastic, with a build area of $21,025 \mathrm{~mm}^{2}$ and a weight of $635.18 \mathrm{~g}$.

\subsection{Design and 3D Printing of a Modified Build Platform Prototype and Resin Tank}

An attachment consisting of twelve compartments to be inserted onto the original resin tank was designed on TinkerCAD (Autodesk Inc., San Rafael, CA, USA). In contrast to the original $200 \mathrm{~mL}$ resin tank, each compartment was designed to contain $10 \mathrm{~mL}$ of photopolymer resin. To match the novel resin tank, a modified version of the build platform featuring twelve build spots $\left({ }_{12} \mathrm{BP}\right)$ was also designed using TinkerCAD. Each spot has a build area of $400 \mathrm{~mm}^{2}$, allowing the fabrication of single tablets up to $20 \mathrm{~mm}$ in diameter. The modified build platform and the resin tank insert were 3D printed with the Form 2 using Clear resin photopolymer; each print was setup using PreForm 2.20.0-Beta 1 (Formlabs Inc., Somerville, MA, USA). The 3D printing of the build platform required $401.38 \mathrm{~mL}$ of photopolymer resin and took $31 \mathrm{~h}$ and $1 \mathrm{~min}$ to be completed. The resin tank insert required $156.33 \mathrm{~mL}$ of photopolymer resin and was completed in $9 \mathrm{~h}$ and $52 \mathrm{~min}$. Both the modified parts were 3D printed at a resolution (layer thickness) of $100 \mu \mathrm{m}$. Following the 3D printing process, each part was placed in propan-2-ol and cleaned in a sonic bath for $20 \mathrm{~min}$ to remove any uncured resin. All the necessary supports were removed after drying for $10 \mathrm{~min}$ at room temperature. The twelve $3 \mathrm{D}$ printed 
compartments were finally fixed to the silicone layer on the original resin tank using silicone glue, while each spot of the $3 \mathrm{D}$ printed ${ }_{12} \mathrm{BP}$ was covered with $75 \mu \mathrm{m}$ thick aluminium tape with an adhesion strength of $12 \mathrm{~N} / \mathrm{cm}$ to allow easy removal of printed tablets.

\subsection{Design and Fabrication of An Aluminium Multi-Build Platform}

A twelve spots aluminium build platform (aluminium ${ }_{12} \mathrm{BP}$ ) was designed using SolidWorks (Dassault Systèmes, Vélizy-Villacoublay, France), based on the design of the 3D printed prototype, manufactured through computer numerical control (CNC) milling and finally bead blasted to provide a rough finishing aimed to increase objects' adherence while printing and to facilitate their release once fabricated; the support fixing the build platform to the SLA apparatus was designed using TinkerCAD and 3D printed with clear resin photopolymer.

\subsection{Tablet Uniformity Testing}

The original build platform (BP), the $3 \mathrm{D}$ printed ${ }_{12} \mathrm{BP}$ and the aluminium ${ }_{12} \mathrm{BP}$ were connected to the SLA apparatus and used to fabricate cylindrical tablets to evaluate the influence of different build platforms on tablet uniformity. Three batches of twelve tablets each were 3D printed on each platform. All tablets manufactured at this stage were composed of Clear Resin photopolymer V4.0 (Formlabs Inc., Somerville, MA, USA). After 3D printing, ten tablets per batch were randomly picked to carry out tablet uniformity tests. Measurements were taken for tablet weight, thickness and diameter. Tablets were designed using TinkerCAD. A conventional cylindrical geometry with a diameter of $12.0 \mathrm{~mm}$ and a thickness of $4.0 \mathrm{~mm}$ was selected and tablets were printed both directly on the build platform and oriented to $45^{\circ}$ using printing supports to evaluate the impact of scaffolds on tablet uniformity. Tablet thickness and diameter were measured using a digital caliper; tablet weight was measured on a precision balance. Statistical analyses were performed using SPSS Version 26.0.0.0 (IBM Corp., Armonk, NY, USA).

\subsection{Formulation of Photopolymer Resins and 3D Printing}

Cylindrical tablet CAD files were uploaded as stereolithographic files (.stl) using PreForm 2.20.0-Beta 1 and set to be printed directly on the build platform. In total, 156 photopolymer formulations were designed based on different combinations of PEGDA 250, PEGDA 575, PEGDA 700, N-vinyl-pyrrolidone, PEG 300, glycerol, propylene glycol and TPO, as described in Table S1. Then, $10 \mathrm{~mL}$ of each formulation was prepared by mixing the liquid photopolymers and eventual fillers with the powdered photoinitiator, and stirred for $12 \mathrm{~h}$ or until complete dissolution of all the ingredients and were kept away from light sources. Then, twelve formulations per time were loaded in the novel resin tank for $3 \mathrm{D}$ printing. Each run took $4.37 \mathrm{~h}$ to be completed at a resolution of $25 \mu \mathrm{m}, 1.95 \mathrm{~h}$ at $50 \mu \mathrm{m}$ and $1.1 \mathrm{~h}$ at $100 \mu \mathrm{m}$.

\subsection{Printability Evaluation}

Photopolymer formulations' printability outcomes were evaluated according to a six-point arbitrary scale (Figure 1). A printability score (PS) from 1 to 6 was assigned to each formulation based on visual inspection. An extra score was assigned to formulations providing 3D printed tablets with a well-defined lower edge. This was introduced to differentiate between formulations showing overcuring only in the first layers rather than the whole tablet. Inclusion criteria were then based on formulations reaching a printability score of 5 and/or showing a defined edge $\left(^{*}\right)$ after printing a cylindrical test tablet. 


\begin{tabular}{cccccccc}
\hline Observation & $\begin{array}{c}\text { No } \\
\text { polymerisation }\end{array}$ & Gelation & Crosslinking & Failed Print & $\begin{array}{c}\text { Successful } \\
\text { Print }\end{array}$ & Overcuring & Tablet Edge \\
\hline Printability Score & 1 & 2 & 3 & 4 & 5 & 6 \\
\hline Comments & $\begin{array}{c}\text { Formulation } \\
\text { remains entirely } \\
\text { liquid }\end{array}$ & Gel-liketexture & $\begin{array}{c}\text { Solid } \\
\text { indistinguishable } \\
\text { debris }\end{array}$ & $\begin{array}{c}\text { Partiallyor } \\
\text { inaccurately } \\
\text { printed object }\end{array}$ & $\begin{array}{c}\text { Fully and } \\
\text { accurately } \\
\text { printed object }\end{array}$ & $\begin{array}{c}\text { Uncontrolled } \\
\text { and extensive } \\
\text { polymerisation }\end{array}$ & $\begin{array}{c}\text { Lower edge } \\
\text { accurately } \\
\text { defined }\end{array}$ \\
\hline
\end{tabular}

Figure 1. Printability scale designed to evaluate photopolymer formulations' printability outcomes.

\subsection{Novel SLA Apparatus Cost-Effectiveness}

The total time required to screen 156 formulations using the novel SLA apparatus, as well as the volume of formulation samples needed and the cost per each formulation prepared, was noted. A cost-effectiveness comparison between the two SLA apparatus was carried out by calculating the time required to screen one formulation at a time using the original apparatus and the costs for preparing $200 \mathrm{~mL}$ of each photopolymer formulation as required by the original capacity resin tank of $200 \mathrm{~mL}$.

\subsection{Resin Recovery Efficiency Evaluation}

The original $\mathrm{BP}$ and the aluminium ${ }_{12} \mathrm{BP}$ were weighed separately. Each platform was then connected to the $3 \mathrm{D}$ printer and a print was initiated. Once the platform was completely lowered in the resin tank and covered in photopolymer resin, the print was aborted to allow the BP to home. As soon as the initial position was reached, a timer was started and the platform collected to be weighed again at given timepoints (Figure 2). The experimental procedure was carried out at room temperature. The volume of resin adhered to the build platform at each timepoint was calculated using Equation (1):

$$
\mathrm{V}_{\mathrm{n}}=\left(\mathrm{w}_{\mathrm{n}}-\mathrm{w}_{\mathrm{i}}\right) / \rho
$$

where $V_{n}$ indicates the volume of resin adhering to the build platform at the n-time point, $\mathrm{w}_{\mathrm{n}}$ is the weight of the build platform at the $\mathrm{n}$-time, $\mathrm{w}_{\mathrm{i}}$ is the initial weight of the build platform and $\rho$ is the resin relative density.

The economic loss relative to the wasted resin at the n-timepoint was calculated using Equation (2):

$$
\text { Economic loss }(£)=\left[\left(w_{n}-w_{i}\right) / \rho\right] \times \text { resin cost }(£ / m L)
$$

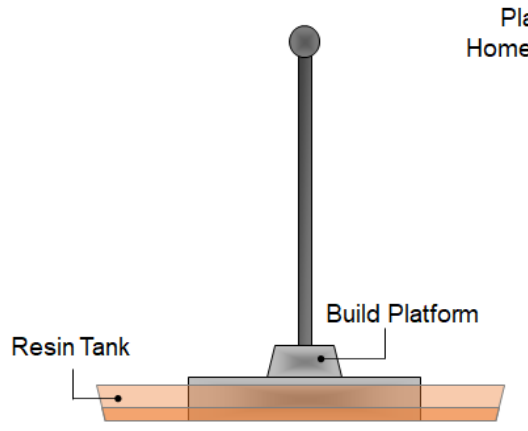

I. The build platform is lowered in the vat. Photopolymer resin adheres to the bottom and the sides of the build platform

Platform Home Position

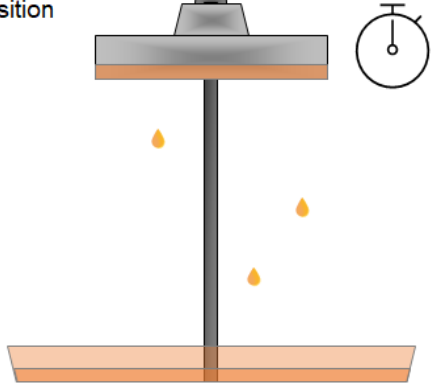

II. As soon as the build platform stops to its home position, a timer is started.



III. At each time point, the build platform is collected to record the amount of resin adhered on its surface

Figure 2. Schematic diagram of the method developed to evaluate photopolymer resin wastage due to adherence on the build platform at the completion of a print. 


\section{Results and Discussion}

\subsection{Stereolithography Apparatus Evolution}

In order to address throughput limitations of conventional vat polymerisation apparatus equipped with a single, large-volume resin tank, the first step in modifying the commercial SLA apparatus was the design of twelve resin compartments and a build platform featuring twelve separate build areas $\left({ }_{12} \mathrm{BP}\right)$ (Figures 3 and 4 ). The dimensions were selected to be the minimum dimensions to allow for tablet printing and resin-depth changes upon submersion of the printing platform.

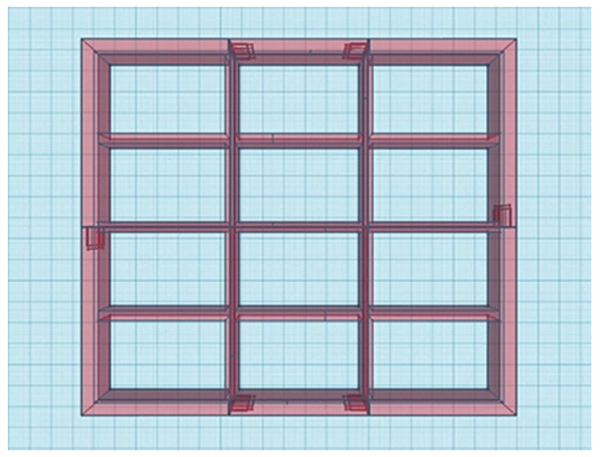

(A)

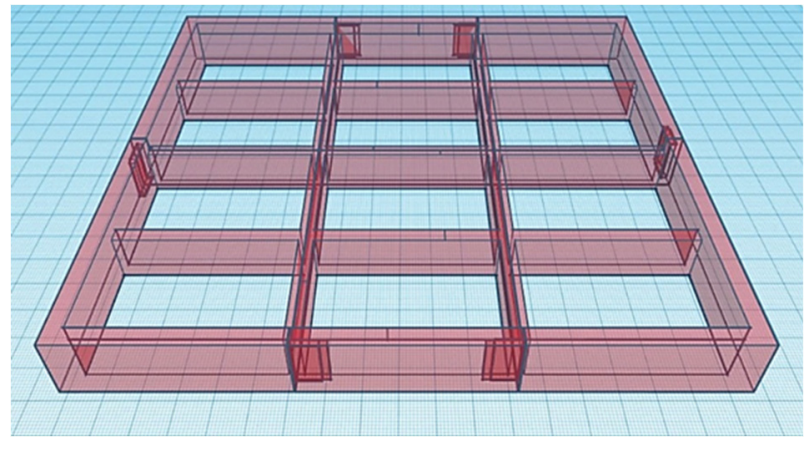

(B)

Figure 3. (A) Top and (B) front view of the CAD model designed for the resin tank insert. Each square on the blue background corresponds to a surface area of $1 \mathrm{~cm}^{2}$.

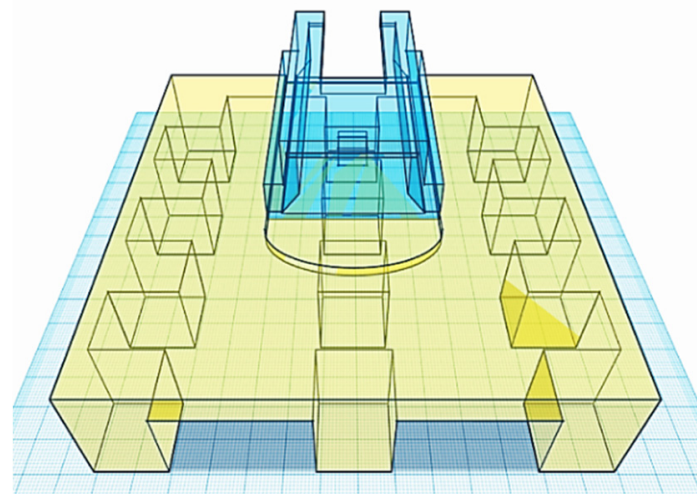

(A)

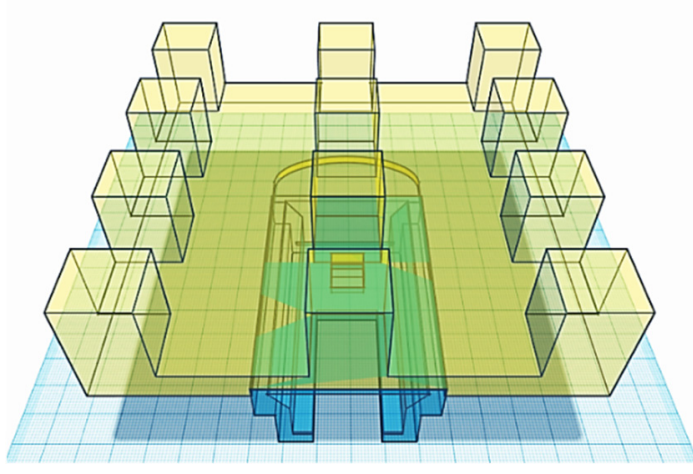

(B)

Figure 4. (A) Top and (B) bottom view of the CAD model used for the twelve-spots build platform ( $\left.{ }_{12} \mathrm{BP}\right)$. Each square on the blue background corresponds to a surface area of $1 \mathrm{~cm}^{2}$.

The CAD files for the novel components were then sent to the 3D printer to be manufactured. The resin tank inserts were fixed onto the original resin tank and tested for being watertight by alternately filling the compartments with a green-coloured solution and leaving them overnight to assess any leaks from the filled compartment to the next ones (Figure $5 \mathrm{~A}, \mathrm{~B}$ ), while the $3 \mathrm{D}$ printed ${ }_{12} \mathrm{BP}$ was covered with aluminium tape to allow for ease of removal of printed dosage forms (Figure 5C). 


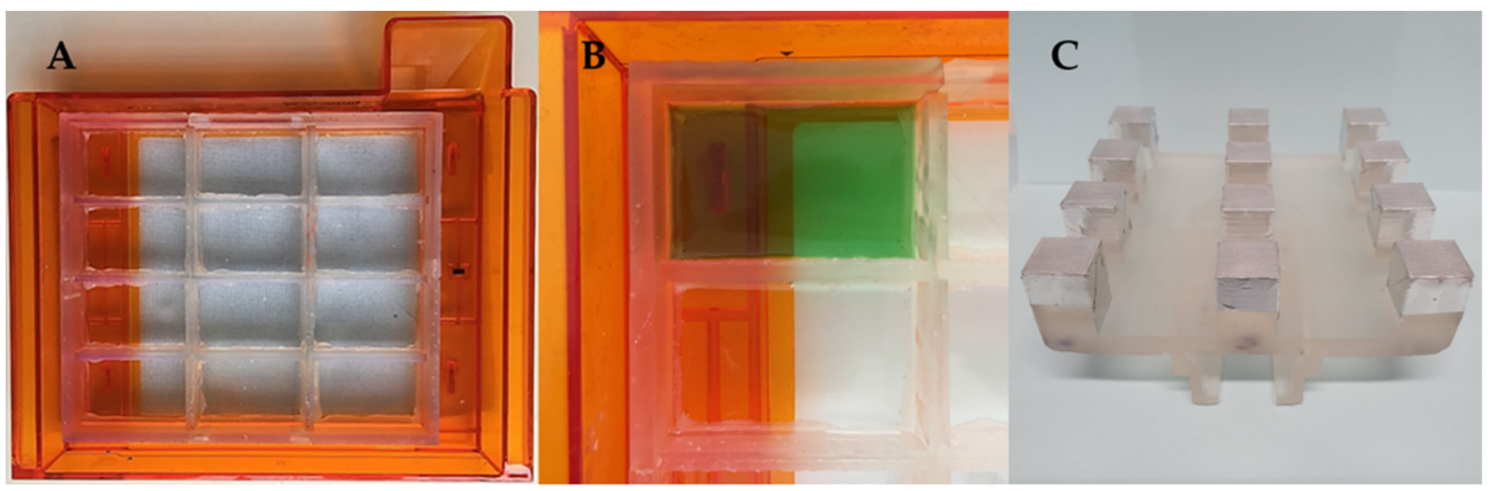

Figure 5. (A) Twelve-vats 3D printed insert placed and fixed onto the silicon layer of the original resin tank, (B) compartments' sealing test, and $(\mathrm{C})$ bottom view of the $3 \mathrm{D}$ printed ${ }_{12} \mathrm{BP}$ showing aluminium tape used to coat each build spot.

Subsequently, after the $3 \mathrm{D}$ printed ${ }_{12} \mathrm{BP}$ was shown to be firmly connected to the printer and compatible with the novel twelve-vats resin tank, a final version of the build platform made of aluminium (aluminium ${ }_{12} \mathrm{BP}$ ) was fabricated through $\mathrm{CNC}$ milling and fixed to the SLA apparatus using a 3D printed joint, which was easily replaceable in the case of breakage (Figure 6). Aluminium was selected due to its similarity to the original component and its density of $2.70 \mathrm{~g} / \mathrm{cm}^{3}$ [40]. The fully assembled aluminium ${ }_{12} \mathrm{BP}$ final weight was $625.15 \mathrm{~g}$, resulting in a $1.58 \%$ decrease in weight compared to the original BP. Such weight was estimated before manufacturing and maintained by drilling holes in the aluminium block (visible in Figure 6A) to obtain a finished product whose weight could not damage the moving parts of the SLA apparatus.

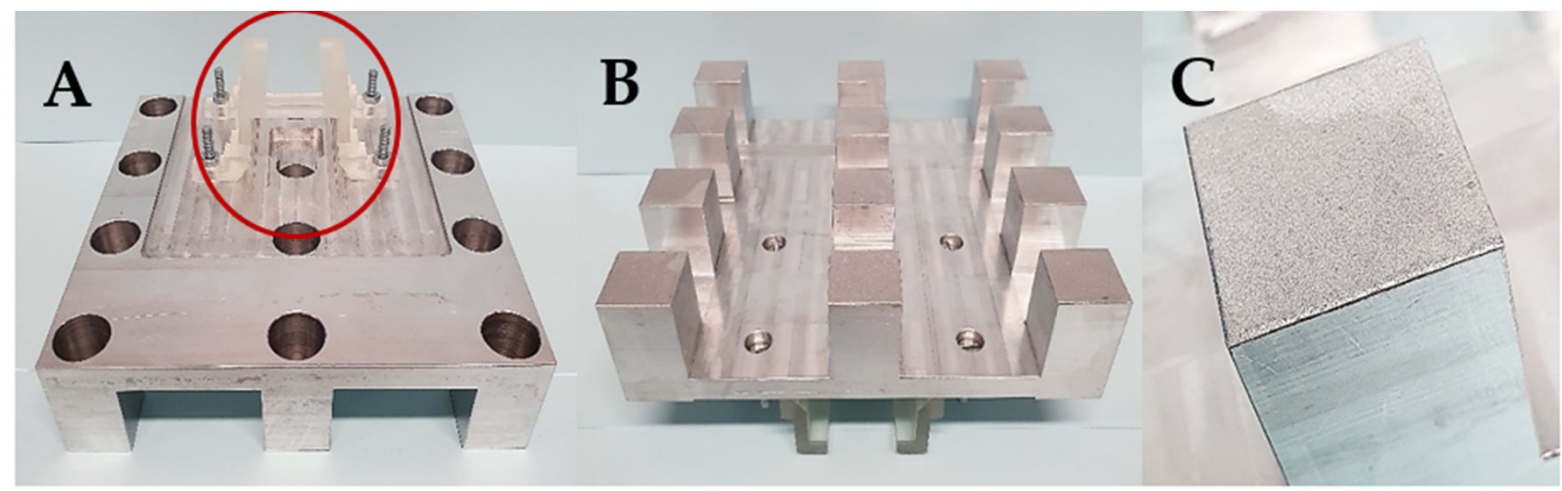

Figure 6. (A) Top and (B) bottom view of the aluminium ${ }_{12} \mathrm{BP}$ fabricated through $\mathrm{CNC}$ milling. The novel design includes hollow build-spots, thus reducing the weight of the platform. A 3D printed attachment (circled in red) allows firm attachment of the platform to the SLA apparatus. (C) Detail of bead-blasted surface of the aluminium ${ }_{12}$ BP. Such a finish was selected to optimise the adhesion of objects during the 3D printing process and to facilitate their release at the end of the print.

With the novel resin tank and build platform in place, a commercial stereolithography apparatus was converted into a piece of equipment able to print multiple formulations at a single time with a fraction of the material originally required (Figure 7). Such novel apparatus was designed with the intention to conduct the high-throughput screening of photopolymer formulations aimed to identify printable candidates to produce solid oral dosage forms. 


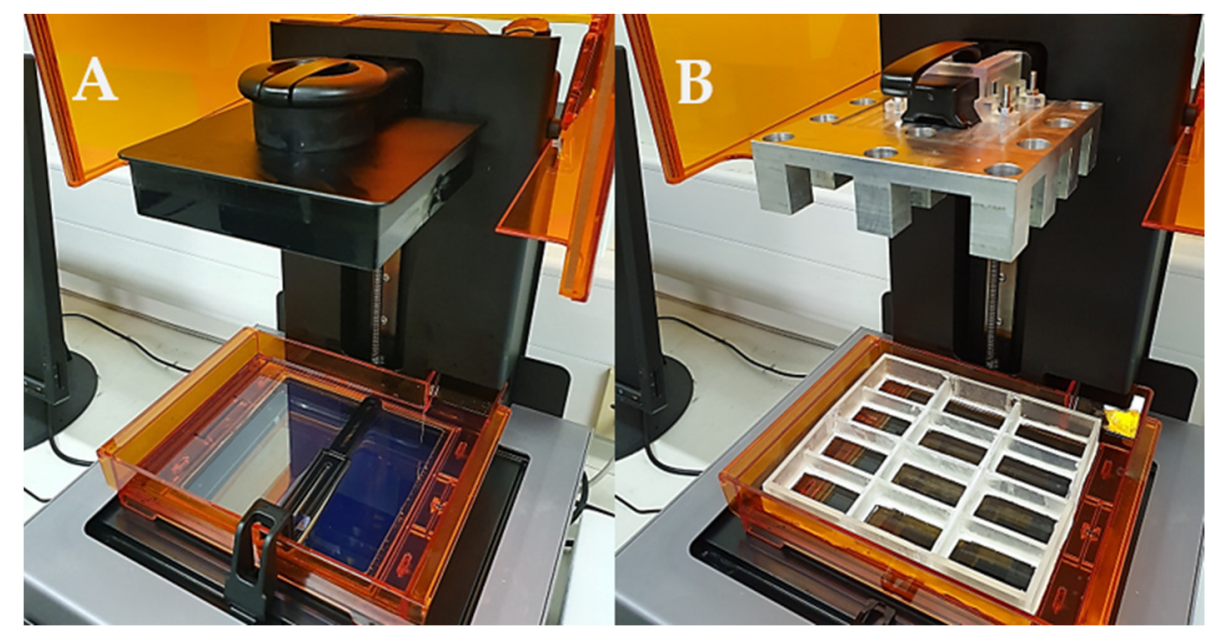

Figure 7. Comparison of (A) the original Form 2 SLA apparatus and (B) the novel SLA apparatus developed. The modified SLA apparatus allows operation with up to twelve different photopolymer formulations simultaneously. Each vat has been designed to contain $10 \mathrm{~mL}$ of resin formulation.

The modified apparatus' reliability was assessed by printing cylindrical tablets using a commercially available resin photopolymer. Twelve tablets were printed on the aluminium ${ }_{12} \mathrm{BP}$, with and without supports (Figure 8). The printability score (PS) assigned to both the types of fabricated tablets was $5^{*}$, indicating a successful print with accurately defined edges in all cases.

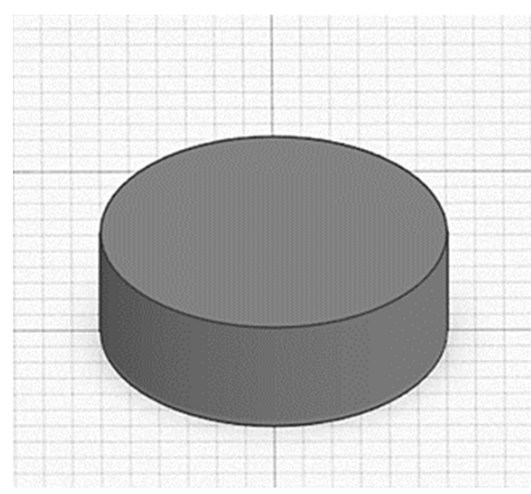

(A)

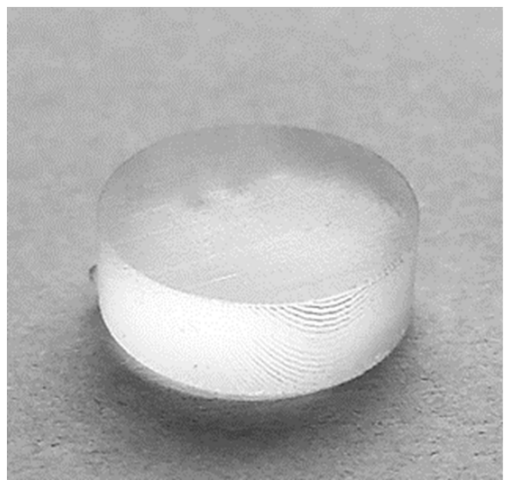

(B)

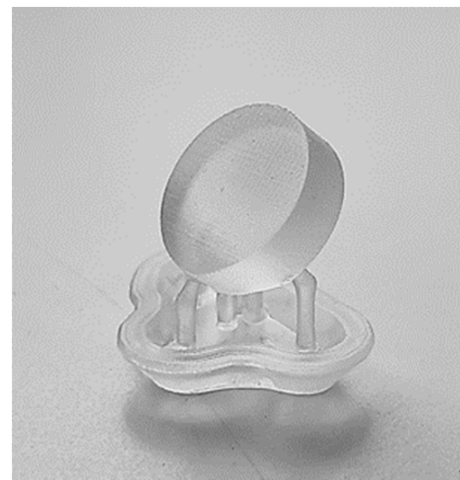

(C)

Figure 8. (A) CAD model and (B) 3D printed cylindrical tablet printed directly on the build platform. (C) Tablet 3D printed using supports.

\subsection{Tablet Uniformity Testing}

Three batches of twelve tablets each were fabricated using the original $\mathrm{BP}$, the 3D printed ${ }_{12} \mathrm{BP}$ and the aluminium ${ }_{12} \mathrm{BP}$. Each batch was $3 \mathrm{D}$ printed with and without supports to evaluate their impact on tablet uniformity. Results for the uniformity of weight, thickness and diameter are shown in Figure 9. 


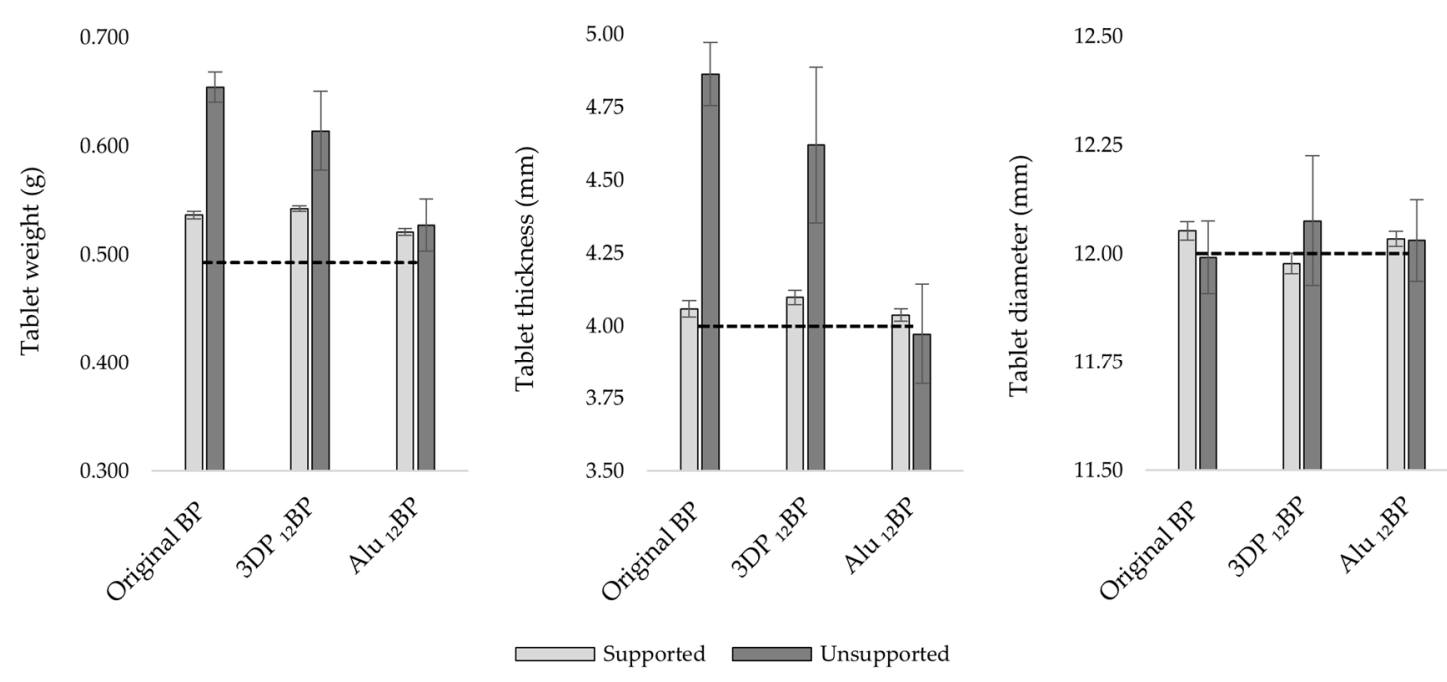

Figure 9. Tablet uniformity of weight (left), thickness (middle), and diameter (right). Black and white bars represent data from tablets printed with and without supports, respectively. Black dashed lines indicate the theoretical value for each parameter. Results were expressed as average $(n=30)$. Error bars indicate standard deviation.

Considering a theoretical value for tablet weight of $0.493 \mathrm{~g}$, estimated from tablet volume and resin density, the percent relative error $\left(\% \mathrm{E}_{\mathrm{r}}\right)$ calculated for the original $\mathrm{BP}$, the $3 \mathrm{D}$ printed ${ }_{12} \mathrm{BP}$ and the aluminium ${ }_{12} \mathrm{BP}$ was $32.67 \%, 24.50 \%$ and $6.90 \%$, respectively, for tablets printed directly on the build platform, while the relative standard deviation (RSD) was $2.15 \%, 5.91 \%$ and $4.56 \%$, respectively. However, the introduction of printing supports resulted in the fabrication of more accurate and precise batches, as shown by a decrease in the $\% \mathrm{E}_{\mathrm{r}}$ and $\mathrm{RSD}$, respectively, to $8.81 \%$ and $0.61 \%$ (original $\mathrm{BP}$ ), $10.05 \%$ and $0.46 \%$ (3D printed ${ }_{12} \mathrm{BP}$ ), $5.64 \%$ and $0.61 \%$ (aluminium $\mathrm{BP}_{12}$ ).

A similar trend was observed when evaluating tablet thickness; when comparing the original $\mathrm{BP}$ and the 3D-printed ${ }_{12} \mathrm{BP}$, there was a $\% \mathrm{E}_{\mathrm{r}}$ of $21.57 \%$ and $15.52 \%$, with an RSD of $2.22 \%$ and $5.77 \%$, respectively, when printing without supports. As per tablet weight, introducing printing scaffolds lowered the $\% \mathrm{E}_{\mathrm{r}}$ and the RSD, respectively, to $1.46 \%$ and $0.69 \%$ (original $\mathrm{BP}$ ), $2.44 \%$ and $0.62 \%$ (3D printed ${ }_{12} \mathrm{BP}$ ). However, tablets printed using the aluminium ${ }_{12} \mathrm{BP}$ showed a $\% \mathrm{E}_{\mathrm{r}}$ and $\mathrm{RSD}$, respectively, of $0.94 \%$ and $0.54 \%$ (with supports), $-0.71 \%$ and $4.34 \%$ (without supports), indicating better uniformity performances when the aluminium ${ }_{12} \mathrm{BP}$ was used.

A more uniform pattern was observed when evaluating tablet diameter. In fact, the $\% \mathrm{E}_{\mathrm{r}}$ observed considering a theoretical diameter of $12 \mathrm{~mm}$ was $0.44 \%(\mathrm{RSD}=0.18 \%)$, $-0.19 \%(\mathrm{RSD}=0.20 \%)$ and $0.29 \%(\mathrm{RSD}=0.15 \%)$ with the original $\mathrm{BP}$, the $3 \mathrm{D}$ printed ${ }_{12} \mathrm{BP}$ and the aluminium ${ }_{12} \mathrm{BP}$, respectively, when printing with supports. Printing tablets directly on the build platform led instead to a $\% \mathrm{E}_{\mathrm{r}}$ of $-0.07 \%(\mathrm{RSD}=0.70 \%), 0.63 \%(\mathrm{RSD}=1.23 \%)$ and $0.26 \%(\mathrm{RSD}=0.78 \%)$ with respect of the original $\mathrm{BP}$, the $3 \mathrm{D}$ printed ${ }_{12} \mathrm{BP}$ and the aluminium ${ }_{12} \mathrm{BP}$.

A multivariate analysis of variance (MANOVA), coupled with a Tukey post hoc test, was performed to evaluate the effect of the build platform used evidenced a statistically significant difference $(p<0.05)$ in tablet weight, thickness and diameter when the 3D printed ${ }_{12} \mathrm{BP}$ was compared to the original $\mathrm{BP}$ and tablets were printed directly on the BP. Comparing weight and thickness uniformity results of unsupported tablets fabricated with the aluminium ${ }_{12} \mathrm{BP}$ and the original $\mathrm{BP}$ also resulted in a statistically significant difference $(p<0.05)$, while no difference $(p>0.05)$ was observed for tablet diameter.

The results firstly suggest that tablet thickness is the most susceptible factor to inhomogeneity; since it is generally observed that the tablet thickness is higher than the expected value, it is likely that this also led to a gain in weight and, therefore, inhomogeneity in tablet weight uniformity. In particular, high differences were related to the use of the $3 \mathrm{D}$-printed ${ }_{12} \mathrm{BP}$. A potential explanation can be found in the loss of structural integrity 
observed in the 3D printed ${ }_{12} \mathrm{BP}$ over time (Figure 10 ). The clear resin photopolymer used to manufacture the $3 \mathrm{D}$ printed ${ }_{12} \mathrm{BP}$ suffers, in fact, from significant limitations in terms of mechanical properties and tends to deform over time and light exposure [41-43]. Even a minimal change in the BP geometry could eventually result in a print with poor dimension accuracy. As aluminium does not share such a limitation, this would explain the significant improvements in tablet uniformity when the aluminium ${ }_{12} \mathrm{BP}$ was used.

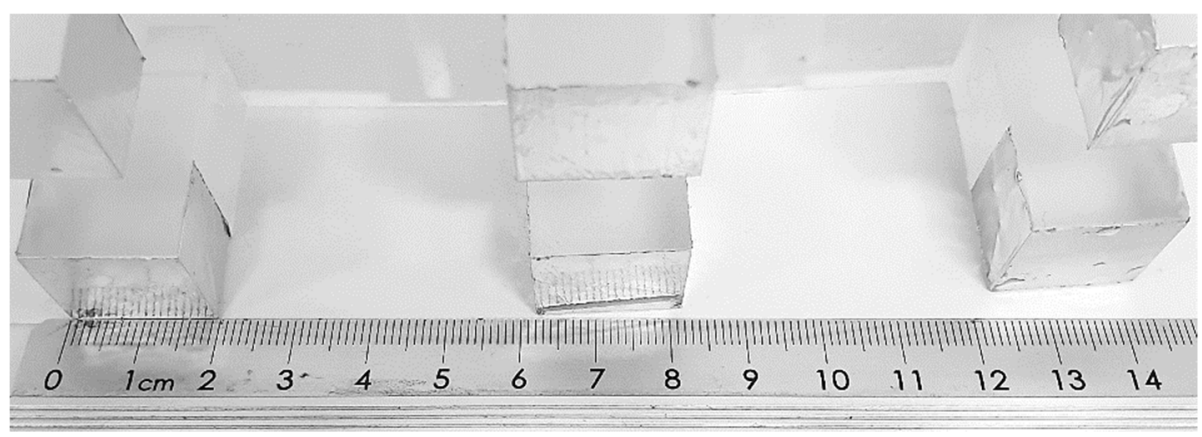

Figure 10. Bending of the $3 \mathrm{D}$ printed ${ }_{12} \mathrm{BP}$ leading to misalignment of the $\mathrm{BP}$ in the SLA apparatus.

Secondly, it was found that introducing printing supports considerably improved tablet uniformity when using the original BP and the $3 \mathrm{D}$ printed ${ }_{12} \mathrm{BP}$. In comparison with the original BP, no statistically significant difference $(p>0.05)$ in weight and thickness uniformity was observed for tablets fabricated on the $3 \mathrm{D}$ printed ${ }_{12} \mathrm{BP}$. Supported tablets printed on the aluminium ${ }_{12} \mathrm{BP}$ also showed no significant difference in terms of uniformity of thickness and diameter when compared to results obtained from tablets produced on the original BP. Such improvements are compatible with the general recommendation to use printing supports for fabricating objects with minimum risk of size inaccuracies [44].

However, it should be considered that printing scaffolds require extra material to be fabricated and are a primary source of waste (Table 1).

Table 1. Weight of 3D-printed tablets and relative supports produced using the original $\mathrm{BP}$ and the $3 \mathrm{D}$-printed ${ }_{12} \mathrm{BP}$. Measurements were taken before and after supports were removed from tablets $(n=10)$. Material waste percentage is expressed as the ratio of support weight over initial weight.

\begin{tabular}{ccc}
\hline Material Waste Assessment & Original BP & 3D Printed ${ }_{\mathbf{1 2}}$ BP \\
\hline Initial weight $(\mathrm{g})$ & 16.096 & 16.280 \\
\hline Supports weight $(\mathrm{g})$ & 12.544 & 16.701 \\
\hline Material waste percentage $(\%)$ & 43.799 & 50.638 \\
\hline
\end{tabular}

\subsection{Resin Recovery Efficiency Evaluation}

At the completion of each print, the BP is automatically lifted and later removed by an operator to collect the fabricated dosage forms, while any uncured resin remaining on the platform is removed and disposed of. Attempts to manually recover resin adhered to the BP using metal tools could result in accidentally recovering partially cured resin debris, or in scratching the aluminium surface with risk to contaminate the feedstock material. Although manual removal determines most of the final resin loss, the amount of material wasted, and its related cost, have not been defined before. As a variable amount of recoverable resin drops from the BP into the resin tank as soon as a print is finished, it was hypothesized that the time the platform was left in the 3D printer before being removed was a critical parameter to estimate the final material wastage. In fact, the longer the BP remains connected to the SLA apparatus, the more photopolymer resin is recovered and saved. Therefore, the impact of the time the BP is left in the 3D printer after a print is completed on the amount of resin eventually wasted was investigated (Figure 11). Both the original 
SLA apparatus and its modified version were compared to assess potential differences in their capacity to generate time-dependent resin waste. Cost implications of such waste generation were also assessed.

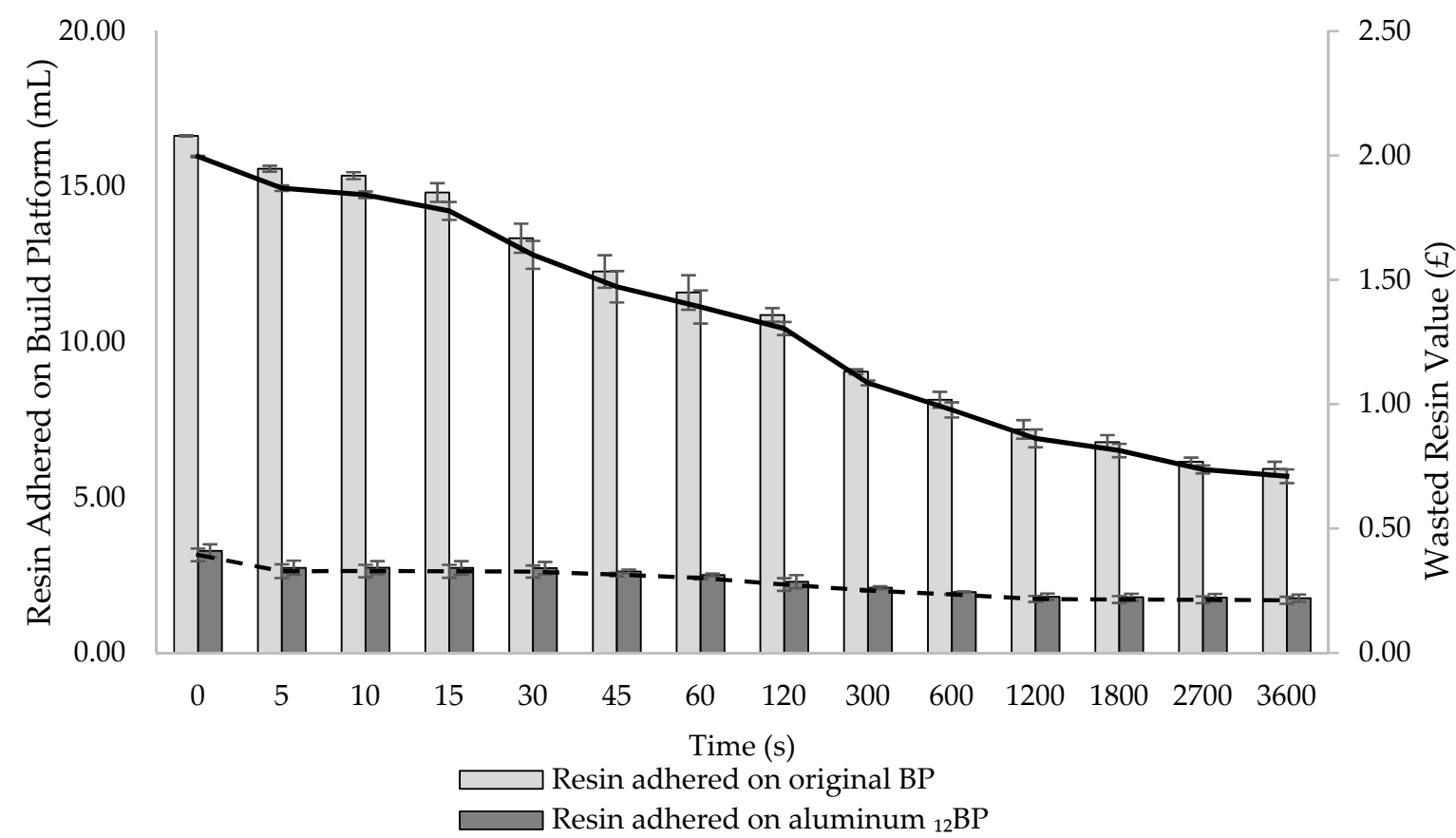

Figure 11. Comparison of photopolymer resin waste generated by adherence onto the original $\mathrm{BP}$ and the aluminum ${ }_{12} \mathrm{BP}$ over a period of one hour. The straight curve indicates the economic loss using the original SLA apparatus. The dashed curve indicates the economic loss using the modified SLA apparatus. Error bars indicate standard deviation of the measurements $(n=3)$.

Measurements were taken at 14 time points covering a period of $1 \mathrm{~h}$. At $\mathrm{t}=0 \mathrm{~s}$, $16.63 \mathrm{~mL}$ of resin adhered to the original BP, while only $3.28 \mathrm{~mL}$ were recorded on the aluminum ${ }_{12} \mathrm{BP}$. At $\mathrm{t}=3600 \mathrm{~s}$, the amount of adhered material was quantified as 5.92 and $1.76 \mathrm{~mL}$ for the original $\mathrm{BP}$ and the aluminium ${ }_{12} \mathrm{BP}$, respectively.

According to the results, it can be stated that, if the BP is left in the SLA apparatus at the end of a print for an increasing amount of time, a clear effect on reducing resin waste is observed. Furthermore, the aluminium ${ }_{12} \mathrm{BP}$ used in the novel SLA apparatus has proven to reduce the amount of adhering resin by $70.27 \%$, in comparison to the original $\mathrm{BP}$; avoiding such waste would allow for the saving of enough material to produce an additional 11 and 3 tablets (based on a $0.5 \mathrm{~mL}$ tablet volume) using the original and the modified SLA apparatus, respectively.

From a cost point of view, the effect of time on material saving, as well as differences between the use of the original and the modified SLA apparatus, are evident (Figure 11). The economic loss due to the resin adhering on the build platforms just returned in position after a print $(\mathrm{t}=0 \mathrm{~s})$ was quantified as GBP 2.00 for the original SLA apparatus versus GBP 0.39 for the modified version. By leaving the platform above the tank until the end of the experiment $(t=3600 \mathrm{~s})$, wasted resin value decreased to GBP 0.71 and GBP 0.21 for the original and the modified build platforms, respectively. It should be noted that the suggested model was based on the use of a commercial photopolymer resin not intended for pharmaceuticals applications. The lack of commercially available resins designed for pharmaceutical manufacturing necessitates the on-site production of photopolymer formulations consisting of polymers, photoinitiators, active pharmaceutical ingredients and other excipients, which eventually increase the final cost per mL. For example, considering the highest cost per $\mathrm{mL}$ for the formulations discussed in this work (Table S1), and assuming comparable materials' behaviour, GBP 4.16 worth of photopolymer resin would be wasted 
at $t=0$ s using the original SLA apparatus, while the resin loss using the modified build platform would be quantified as GBP 0.82 at the same timepoint. Recovering photopolymer resin from the build platforms for one hour would instead decrease the value of wasted material to GBP 1.48 and GBP 0.44 using the original and the modified SLA apparatus, respectively.

Ultimately, our findings aim to suggest a potential solution to minimise photopolymer resin wastage by avoiding the immediate removal of the build platform after the completion of dosage forms of 3D printing. This would, in fact, allow a certain amount of resin to be time-dependently recovered and reused, with no need of operator intervention. While the effect of time and the type of BP used have been evaluated, other factors, such as photopolymer resins' viscosity and surface tension, should also be investigated, in order to establish a solid model to universally predict material wastage and identify the amount of time providing the highest recovery.

In fact, it is likely that the production of personalised dosage forms in clinical settings, such as hospital pharmacies, will have higher costs than the mass production of drugs at an industrial level, and it is, therefore, necessary to maximise process cost-effectiveness [45].

\subsection{High-Throughput Screening of Pharmaceutical Photopolymer Formulations}

\subsubsection{Novel SLA Apparatus Cost-Effectiveness Evaluation}

The modified SLA apparatus was used to carry out a printability screening of 156 pharmaceutical photopolymer formulations. The total time required for the screening, formulations amount needed, and the related costs are reported in Table 2. A comparison of the same parameters estimated considering the use of the original apparatus is also delineated.

Table 2. Cost-effectiveness comparison of the two SLA apparatus used to screen 156 pharmaceutical photopolymer formulations.

\begin{tabular}{cccc}
\hline Apparatus Used & Time (h) & Sample Required (L) & Materials Cost (GBP) \\
\hline Modified SLA Apparatus & 96.42 & 1.56 & 292.21 \\
\hline Original SLA Apparatus & 1157.00 & 31.20 & 5844.19 \\
\hline
\end{tabular}

The developed modified SLA apparatus proved to dramatically reduce both the time and the sample amount required to conduct systematic screening of photopolymer formulations. In particular, the use of the novel SLA apparatus resulted in a $91.66 \%$ reduction in the amount of time needed to complete the screening, and 95\% less raw materials being used.

These results make the introduction of the modified apparatus into formulation development processes a promising tool to enhance the application of SLA 3D printing in pharmaceutics, which has been limited until now. Furthermore, our aim was to bridge the gap between general use SLA equipment and those designed for research applications, with the view of developing SLA 3D printers specifically designed for pharmaceutical purposes in the future.

\subsubsection{Printability Outcomes Evaluation}

Based on the inclusion criteria, the whole set of photopolymer formulations screened was classified in four groups (Figure 12). Out of the 156 formulations tested, 96 provided a PS $\neq 5$ indicating poor printability outcomes (Figure 12, group A), while the remaining 60 formulations met the eligibility criteria by reaching a PS $=5$ or showing defined edges $\left({ }^{*}\right)$ with at least one printing resolution, making up a pool labelled as Printable Formulations (PF, $n=60$ ) (Figure 12, group B). 
Results distribution of photopolymer formulations screened

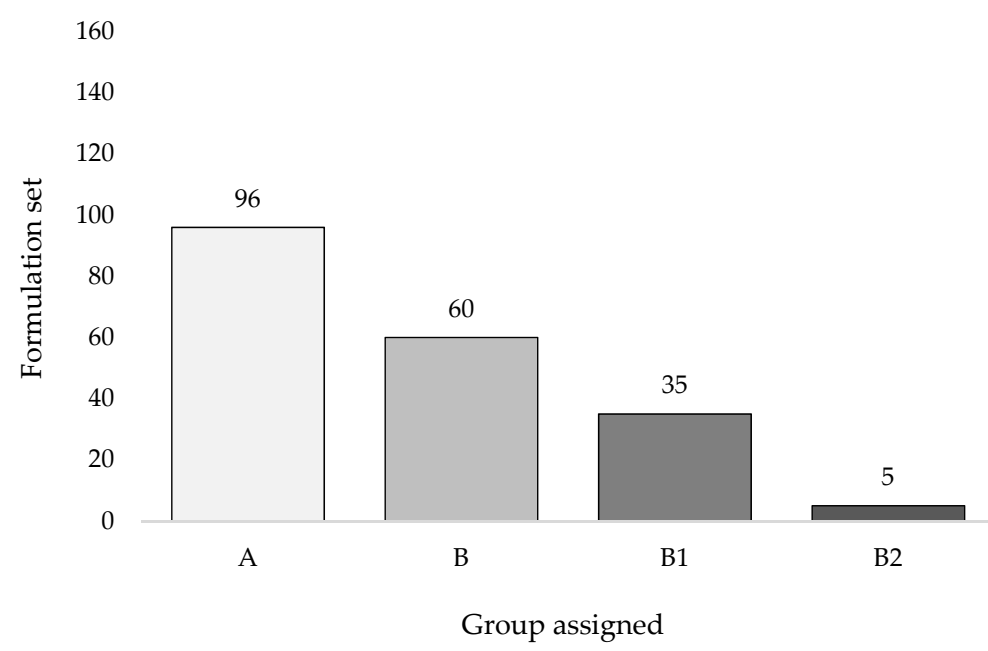

Figure 12. Group classification of photopolymer formulations screened. Group A indicates formulations with $\mathrm{PS} \neq 5(n=96)$; group $\mathrm{B}$ reports formulations with a PS $=5$ or PS $={ }^{*}$ at least at one printing resolution $(n=60)$; groups B1 $(n=35)$ and B2 $(n=5)$ list formulations with a PS $=5^{*}$ at least at one or at each printing resolution used, respectively.

Formulations included in group B were then subclassified into groups B1 $(n=35$; formulations reaching PS $=5^{*}$ at least for one printing resolution) and $\mathrm{B} 2(n=5$; formulations reaching $\mathrm{PS}=5^{*}$ at each printing resolution). Formulations belonging to groups $\mathrm{B} 1$ and B2 were jointly labelled as Best Formulations (BF, $n=40)$.

A detailed table, including the composition of each formulation, the printability score assigned at each resolution, and the group to which it belongs, is shown in Table S1.

The effect of 3D printing resolution on printability outcomes was also investigated (Figure 13). Selecting a resolution of $25 \mu \mathrm{m}$ resulted in $43.3 \%$ of group B formulations being classified as BF, followed by $30.0 \%$ and $33.3 \%$ selecting a resolution of 50 and $100 \mu \mathrm{m}$, respectively. In total, $33.3 \%$ of group $\mathrm{B}$ formulations were instead classified as PF when screened at $50 \mu \mathrm{m}$, while a reduction to $28.3 \%$ and $20.0 \%$ was observed when printing at 25 and $100 \mu \mathrm{m}$, respectively. Overall, of all the formulations classified in group B, 71.7\% met targeted printability criteria using a printing resolution of $25 \mu \mathrm{m}$, whereas a decrease in printing resolution to 50 and $100 \mu \mathrm{m}$ also reduced the fraction of formulations providing satisfactory outcomes to $63.3 \%$ and $53.3 \%$, respectively.

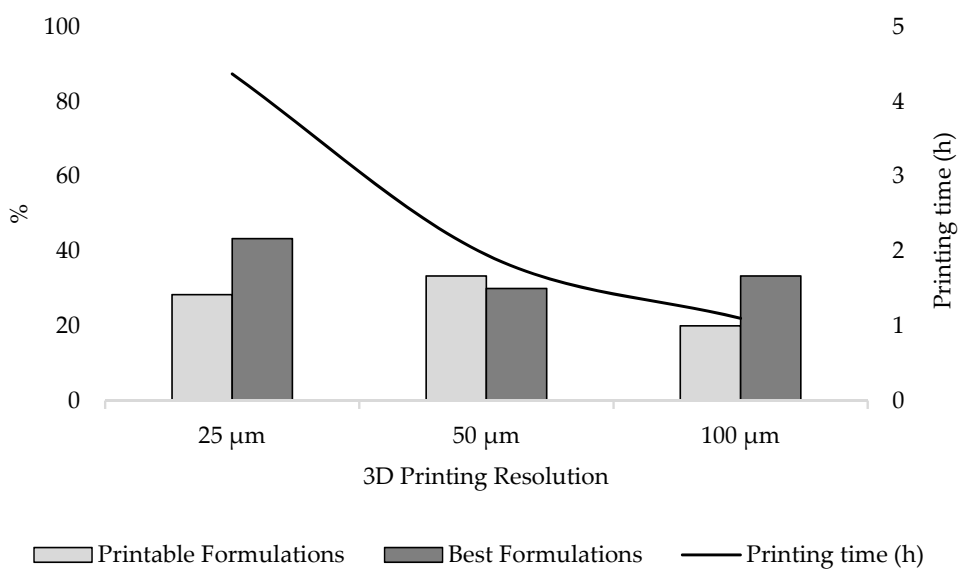

Figure 13. 3D printing resolution effect on printability outcomes. Printable Formulations and Best Formulations are expressed as a percentage of Group B $(n=60)$. The black line indicates the printing time required to complete a 12 -formulations screening. 
It should, however, be considered that printing with a resolution of $25 \mu \mathrm{m}$ increases printing time by $55.38 \%$ and $74.83 \%$ compared to using a layer thickness of 50 and $100 \mu \mathrm{m}$, respectively. Despite the better results observed using higher resolution, the increase in production time should not be underestimated. The implementation of SLA 3D printing in clinical settings to produce personalised dosage forms will in fact be possible if the overall efficiency of the process is optimised, reducing costs and production times, and ensuring the safety and efficacy of the printed medicines $[45,46]$. It is, therefore, essential to identify novel formulations, designed to provide best printability even at low resolution.

Our systematic screening has shown how modifying a commercial SLA apparatus allows us to address the limitation of identifying printable resin formulations with a significant reduction both in terms of time and costs. Furthermore, the application of the modified SLA apparatus in a clinical scenario would allow for the printing of multiple formulations at the same time to provide patients with their personalised medicines in reasonable time.

\section{Conclusions}

A commercial SLA apparatus was modified into a novel, multimaterial device specifically designed to address the limitations of SLA 3D printing in pharmaceutical applications. The novel SLA apparatus was tested by carrying out a high-throughput screening to identify pharmaceutical photopolymer formulations with satisfactory printability and was proved to considerably reduce the time and economic resources needed. Furthermore, potential areas of wastage were identified and solutions to address them were described with the view to enhance SLA 3D printing feasibility at a clinical level. In conclusion, the novel apparatus' power to 3D print different formulations at the same time may not only be advantageous at a formulation development stage, but also in clinical scenarios where different solid oral dosage forms can be produced together using the same 3D printer, making access to personalised medicines to patients more achievable.

Supplementary Materials: The following are available online at https:/ /www.mdpi.com/article/10 .3390 / pharmaceutics13050616/s1, Table S1: \% w/w composition of the 156 photopolymer formulations prepared and screened. Printability score assigned per formulation at each printing resolution tested and the classification group of each formulation are reported. Costs $/ \mathrm{mL}$ per formulation are described in the right column.

Author Contributions: Conceptualisation, C.A.R., D.J.K. and C.C.; methodology, C.C.; software, C.A.R., C.C.; data curation, C.A.R., C.C.; writing-original draft preparation, C.C.; writing-review and editing, C.A.R., D.J.K., and C.C.; visualisation, C.C.; supervision, C.A.R. and D.J.K.; funding acquisition, C.A.R. and D.J.K. All authors have read and agreed to the published version of the manuscript.

Funding: This research was funded by Aston University.

Institutional Review Board Statement: Not applicable.

Informed Consent Statement: Not applicable.

Data Availability Statement: The data presented in this study are contained within this article.

Acknowledgments: We thankfully acknowledge Tayyibah Hussain for her valuable contribution to data collection and Michael Rowley for his precious support with the CNC manufacturing at the Aston University Engineering Workshop.

Conflicts of Interest: The authors declare no conflict of interest.

\section{References}

1. ISO/ASTM 52900:2015(en), Additive Manufacturing-General Principles-Terminology. Available online: https://www.iso.org/ obp/ui/\#iso:std:iso-astm:52900:ed-1:v1:en (accessed on 8 October 2018).

2. ZipDose Technology ISpritam / Aprecia. Available online: https://www.aprecia.com/technology/zipdose (accessed on 9 February 2021). 
3. Trenfield, S.J.; Awad, A.; Goyanes, A.; Gaisford, S.; Basit, A.W. 3D Printing Pharmaceuticals: Drug Development to Frontline Care. Trends Pharm. Sci. 2018, 39, 440-451. [CrossRef] [PubMed]

4. Kyobula, M.; Adedeji, A.; Alexander, M.R.; Saleh, E.; Wildman, R.; Ashcroft, I.; Gellert, P.R.; Roberts, C.J. 3D inkjet printing of tablets exploiting bespoke complex geometries for controlled and tuneable drug release. J. Control. Release 2017, 261, 207-215. [CrossRef] [PubMed]

5. Triastek Receives FDA IND Clearance for 3D Printed Drug to Treat Rheumatoid Arthritis-3D Printing Industry. Available online: https: / /3dprintingindustry.com/news/triastek-receives-fda-ind-clearance-for-3d-printed-drug-to-treat-rheumatoidarthritis-184159/ (accessed on 15 February 2021).

6. Graham, E. Improving Outcomes Through Personalised Medicine. NHS Engl. 2016, 6-10.

7. Curti, C.; Kirby, D.J.; Russell, C.A. Current formulation approaches in design and development of solid oral dosage forms through three-dimensional printing. Prog. Addit. Manuf. 2020, 5, 111-123. [CrossRef]

8. Ligon, S.C.; Liska, R.; Stampfl, J.; Gurr, M.; Mülhaupt, R. Polymers for 3D Printing and Customized Additive Manufacturing. Chem. Rev. 2017, 117, 10212-10290. [CrossRef]

9. Ghanizadeh Tabriz, A.; Nandi, U.; Hurt, A.P.; Hui, H.W.; Karki, S.; Gong, Y.; Kumar, S.; Douroumis, D. 3D printed bilayer tablet with dual controlled drug release for tuberculosis treatment. Int. J. Pharm. 2021, 593, 120147. [CrossRef] [PubMed]

10. Ayyoubi, S.; Cerda, J.R.; Fernández-García, R.; Knief, P.; Lalatsa, A.; Healy, A.M.; Serrano, D.R. 3D printed spherical mini-tablets: Geometry versus composition effects in controlling dissolution from personalised solid dosage forms. Int. J. Pharm. 2021, 597, 120336. [CrossRef]

11. Li, P.; Jia, H.; Zhang, S.; Yang, Y.; Sun, H.; Wang, H.; Pan, W.; Yin, F.; Yang, X. Thermal Extrusion 3D Printing for the Fabrication of Puerarin Immediate-Release Tablets. AAPS PharmSciTech 2020, 21, 1-10. [CrossRef]

12. Đuranović, M.; Obeid, S.; Madžarević, M.; Cvijić, S.; Ibrić, S. Paracetamol extended release FDM 3D printlets: Evaluation of formulation variables on printability and drug release. Int. J. Pharm. 2021, 592, 120053. [CrossRef] [PubMed]

13. Fina, F.; Goyanes, A.; Madla, C.M.; Awad, A.; Trenfield, S.J.; Kuek, J.M.; Patel, P.; Gaisford, S.; Basit, A.W. 3D printing of drug-loaded gyroid lattices using selective laser sintering. Int. J. Pharm. 2018, 547, 44-52. [CrossRef]

14. Fina, F.; Madla, C.M.; Goyanes, A.; Zhang, J.; Gaisford, S.; Basit, A.W. Fabricating 3D printed orally disintegrating printlets using selective laser sintering. Int. J. Pharm. 2018, 541, 101-107. [CrossRef]

15. Fina, F.; Goyanes, A.; Gaisford, S.; Basit, A.W. Selective laser sintering (SLS) 3D printing of medicines. Int. J. Pharm. 2017, 529, 285-293. [CrossRef] [PubMed]

16. Hamed, R.; Mohamed, E.M.; Rahman, Z.; Khan, M.A. 3D-printing of lopinavir printlets by selective laser sintering and quantification of crystalline fraction by XRPD-chemometric models. Int. J. Pharm. 2021, 592, 120059. [CrossRef] [PubMed]

17. Gueche, Y.A.; Sanchez-Ballester, N.M.; Bataille, B.; Aubert, A.; Leclercq, L.; Rossi, J.C.; Soulairol, I. Selective Laser Sintering of Solid Oral Dosage Forms with Copovidone and Paracetamol Using a CO2 Laser. Pharmaceutics 2021, 13, 160. [CrossRef] [PubMed]

18. Wang, J.; Goyanes, A.; Gaisford, S.; Basit, A.W. Stereolithographic (SLA) 3D printing of oral modified-release dosage forms. Int. J. Pharm. 2016, 503, 207-212. [CrossRef] [PubMed]

19. Robles-Martinez, P.; Goyanes, A.; Basit, A.W.; Gaisford, S. Fabrication of drug-loaded hydrogels with stereolithographic 3D printing. Int. J. Pharm. 2017, 532, 313-317. [CrossRef]

20. Krkobabić, M.; Medarević, D.; Cvijić, S.; Grujić, B.; Ibrić, S. Hydrophilic excipients in digital light processing (DLP) printing of sustained release tablets: Impact on internal structure and drug dissolution rate. Int. J. Pharm. 2019, 572, 118790. [CrossRef]

21. Kadry, H.; Wadnap, S.; Xu, C.; Ahsan, F. European Journal of Pharmaceutical Sciences Digital light processing (DLP) 3D-printing technology and photoreactive polymers in fabrication of modi fi ed-release tablets. Eur. J. Pharm. Sci. 2019, 135, 60-67. [CrossRef]

22. Madžarević, M.; Ibrić, S. Evaluation of exposure time and visible light irradiation in LCD 3D printing of ibuprofen extended release tablets. Eur. J. Pharm. Sci. 2021, 158, 105688. [CrossRef] [PubMed]

23. Stanojević, G.; Medarević, D.; Adamov, I.; Pešić, N.; Kovačević, J.; Ibrić, S. Tailoring Atomoxetine Release Rate from DLP 3D-Printed Tablets Using Artificial Neural Networks: Influence of Tablet Thickness and Drug Loading. Molecules 2020, $26,111$. [CrossRef]

24. Goyanes, A.; Buanz, A.B.M.; Hatton, G.B.; Gaisford, S.; Basit, A.W. 3D printing of modified-release aminosalicylate (4-ASA and 5-ASA) tablets. Eur. J. Pharm. Biopharm. 2015, 89, 157-162. [CrossRef]

25. Kempin, W.; Domsta, V.; Grathoff, G.; Brecht, I.; Semmling, B.; Tillmann, S.; Weitschies, W.; Seidlitz, A. Immediate Release 3D-Printed Tablets Produced Via Fused Deposition Modeling of a Thermo-Sensitive Drug. Pharm. Res. 2018, 35, 1-12. [CrossRef] [PubMed]

26. Ilyés, K.; Krisztián, N.; Balogh, A.; Farkas, B. The applicability of pharmaceutical polymeric blends for the fused deposition modelling (FDM) 3D technique: Material considerations-Printability-Process modulation, with consecutive effects on in vitro release, stability and degradation. Eur. J. Pharm. Sci. 2019, 129, 110-123. [CrossRef] [PubMed]

27. Vo, A.Q.; Zhang, J.; Nyavanandi, D.; Bandari, S.; Repka, M.A. Hot melt extrusion paired fused deposition modeling 3D printing to develop hydroxypropyl cellulose based floating tablets of cinnarizine. Carbohydr. Polym. 2020, 246, 116519. [CrossRef] [PubMed]

28. Ruggi, D.; Lupo, M.; Sofia, D.; Barrès, C.; Barletta, D.; Poletto, M. Flow properties of polymeric powders for selective laser sintering. Powder Technol. 2020, 370, 288-297. [CrossRef]

29. Januskaite, P.; Xu, X.; Ranmal, S.R.; Gaisford, S.; Basit, A.W.; Tuleu, C.; Goyanes, A. I Spy with My Little Eye: A Paediatric Visual Preferences Survey of 3D Printed Tablets. Pharmaceutics 2020, 12, 1100. [CrossRef] [PubMed] 
30. Fastø, M.M.; Genina, N.; Kaae, S.; Kälvemark Sporrong, S. Perceptions, preferences and acceptability of patient designed 3D printed medicine by polypharmacy patients: A pilot study. Int. J. Clin. Pharm. 2019, 41, 1290-1298. [CrossRef]

31. Azad, M.A.; Olawuni, D.; Kimbell, G.; Badruddoza, A.Z.M.; Hossain, M.S.; Sultana, T. Polymers for extrusion-based 3D printing of pharmaceuticals: A holistic materials-process perspective. Pharmaceutics 2020, 12, 124. [CrossRef] [PubMed]

32. Robles-Martinez, P.; Xu, X.; Trenfield, S.J.; Awad, A.; Goyanes, A.; Telford, R.; Basit, A.W.; Gaisford, S. 3D Printing of a Multi-Layered Polypill Containing Six Drugs Using a Novel Stereolithographic Method. Pharmaceutics 2019, 11, 274. [CrossRef]

33. Steyrer, B.; Neubauer, P.; Liska, R.; Stampfl, J. Visible light photoinitiator for 3D-printing of tough methacrylate resins. Materials 2017, 10, 1445. [CrossRef]

34. Voet, V.S.D.; Strating, T.; Schnelting, G.H.M.; Dijkstra, P.; Tietema, M.; Xu, J.; Woortman, A.J.J.; Loos, K.; Jager, J.; Folkersma, R. Biobased Acrylate Photocurable Resin Formulation for Stereolithography 3D Printing. ACS Omega 2018, 3, 1403-1408. [CrossRef]

35. Melia, C.D.; Davis, S.S. Review article: Mechanisms of drug release from tablets and capsules. I: Disintegration. Aliment. Pharm. 1989, 3, 223-232. [CrossRef]

36. Sheela, U.B.; Usha, P.G.; Joseph, M.M.; Melo, J.S.; Thankappan Nair, S.T.; Tripathi, A. 3D Printing in Medicine and Surgery, 1st ed.; Elsevier: Amsterdam, The Netherlands, 2020; pp. 83-104.

37. Kurzmann, C.; Janjić, K.; Shokoohi-Tabrizi, H.; Edelmayer, M.; Pensch, M.; Moritz, A.; Agis, H. Evaluation of Resins for Stereolithographic 3D-Printed Surgical Guides: The Response of L929 Cells and Human Gingival Fibroblasts. Biomed. Res. Int. 2017, 2017, 4057612. [CrossRef]

38. Robles-Martinez, P.; Goyanes, A.; Basit, A.W.; Gaisford, S. Influence of Geometry on the Drug Release Profiles of Stereolithographic (SLA) 3D-Printed Tablets. AAPS PharmSciTech 2018, 19, 3355-3361. [CrossRef]

39. Poppendieck, M. Principles of lean thinking. IT Manag. Sel. 2011, 18, 1-7.

40. Latief, F.H.; Sherif, E.S.M. Effects of sintering temperature and graphite addition on the mechanical properties of aluminum. J. Ind. Eng. Chem. 2012, 18, 2129-2134. [CrossRef]

41. Hada, T.; Kanazawa, M.; Iwaki, M.; Arakida, T.; Minakuchi, S. Effect of printing direction on stress distortion of three-dimensional printed dentures using stereolithography technology. J. Mech. Behav. Biomed. Mater. 2020, 110, 103949. [CrossRef] [PubMed]

42. Feng, X.; Yang, Z.; Chmely, S.; Wang, Q.; Wang, S.; Xie, Y. Lignin-coated cellulose nanocrystal filled methacrylate composites prepared via 3D stereolithography printing: Mechanical reinforcement and thermal stabilization. Carbohydr. Polym. 2017, 169, 272-281. [CrossRef] [PubMed]

43. Invernizzi, M.; Suriano, R.; Muscatello, A.; Turri, S.; Levi, M. Near-visible stereolithography of a low shrinkage cationic/freeradical photopolymer blend and its nanocomposite. J. Appl. Polym. Sci. 2020, 137, 48333. [CrossRef]

44. Jiang, J.; Lou, J.; Hu, G. Effect of support on printed properties in fused deposition modelling processes. Virtual Phys. Prototyp. 2019, 14, 308-315. [CrossRef]

45. Rautamo, M.; Kvarnström, K.; Sivén, M.; Airaksinen, M.; Lahdenne, P.; Sandler, N. Benefits and Prerequisites Associated with the Adoption of Oral 3D-Printed Medicines for Pediatric Patients: A Focus Group Study among Healthcare Professionals. Pharmaceutics 2020, 12, 229. [CrossRef] [PubMed]

46. Awad, A.; Trenfield, S.J.; Gaisford, S.; Basit, A.W. 3D printed medicines: A new branch of digital healthcare. Int. J. Pharm. 2018, 548, 586-596. [CrossRef] [PubMed] 